\title{
Body Composition, Resting Energy Expenditure, and Metabolic Changes in Women Diagnosed with Differentiated Thyroid Carcinoma
}

\author{
Elena Izkhakov, ${ }^{1-3}$ Nachum Vaisman, ${ }^{4}$ Sophie Barnes, ${ }^{2,5}$ Micha Barchana, ${ }^{3}$ \\ Naftali Stern, ${ }^{1,2}$ and Lital Keinan-Boker ${ }^{3,6}$
}

Background: Thyroid hormones heavily impact energy expenditure, body mass, and body composition. Their role in the state of exogenous subclinical hyperthyroidism in differentiated thyroid carcinoma (DTC) patients, however, is less well defined. The first aim of this study was to assess changes in body weight, body composition, resting energy expenditure (REE), respiratory quotient (RQ), and metabolic parameters in female DTC patients, starting from the phase of a euthyroid state before total thyroidectomy through the subsequent year after thyrotropin (TSH) suppression. The second aim was to assess the relationship between these variables and thyroid function parameters. Methods: This observational case series analyzed changes in body composition, calorimetric, and metabolic parameters of 15 DTC female patients at 5 time points: (1) at initial DTC diagnosis (euthyroid state), (2) at 2-3 weeks after thyroidectomy (hypothyroid state), (3) at 2-3 months of levothyroxine (LT4) treatment (exogenous euthyroid state), (4) after 6-9 months, and (5) after 1 year of TSH suppressive LT4 therapy (exogenous subclinical hyperthyroid state). A generalized estimating equation (GEE) analysis was performed to estimate the longitudinal correlations of the total triiodothyronine (TT3)/free thyroxine (fT4) ratio (as an independent variable) with body composition, metabolic, and calorimetric parameter changes (as dependent variables).

Results: REE, REE per kilogram of lean body mass (REE/LBM), pulse, and systolic and diastolic blood pressure were significantly higher after TSH suppressive LT4 therapy. The GEE analysis revealed longitudinal negative correlations between the TT3/fT4 ratio and systolic blood pressure, fasting blood glucose, body mass index, android (abdominal wall and visceral mesentery) fat distribution, trunk, and arm fat distribution, REE, and REE/LBM. There was a positive correlation with RQ.

Conclusions: REE, REE/LBM, pulse, and systolic and diastolic blood pressure were significantly higher after thyroidectomy, radioiodine and TSH suppressive therapy in female DTC patients, while no changes were observed in body weight or body composition. A lower TT3/fT4 ratio longitudinally correlated with increases in REE, REE/ LBM, abdominal fat distribution, systolic blood pressure, and fasting blood glucose, as well as with decreased RQ. These findings highlight the importance of judicial balancing of the benefits and detriments of TSH suppression with subsequent decreased TT3/fT4 ratios for female DTC patients.

Keywords: thyroid carcinoma, subclinical hyperthyroidism, resting energy expenditure, metabolic changes, body composition

\section{Introduction}

T HE IMPORTANT ROLE of thyroid hormones in determining energy expenditure (EE), body mass, and body composition is well established $(1,2)$. EE can increase or decrease by
$50 \%$ in a state of hyper- or hypothyroidism, respectively (1). Several studies have shown a positive relationship between thyrotropin (TSH) and triiodothyronine (T3) with obesity, body mass index (BMI), and metabolic parameters in the euthyroid state (3-6). Several other studies have suggested an

\footnotetext{
${ }^{1}$ Institute of Endocrinology, Metabolism and Hypertension; ${ }^{4}$ Unit of Clinical Nutrition; ${ }^{5}$ Department of Ultrasound Division of Imaging; Tel Aviv Sourasky Medical Center, Tel Aviv, Israel.

${ }^{2}$ Sackler Faculty of Medicine, Tel Aviv University, Tel Aviv, Israel.

${ }^{3}$ School of Public Health, Faculty of Social Welfare and Health Sciences, University of Haifa, Haifa, Israel.

${ }^{6}$ National Cancer Registry, Israel Center for Disease Control, Ministry of Health, Ramat Gan, Israel.
} 
opposite direction for the cause-and-effect, wherein increasing TSH levels reflect an adaptation process against weight gain to increase $\mathrm{EE}(1,7)$. Thus, it remains unclear whether high TSH levels are responsible for obesity or a consequence of obesity. Less conclusive are the effects of thyroid hormones on body weight, body composition, metabolic parameters, and EE in subclinical hyper- or hypothyroidism states, and particularly in the setting of exogenous hormonal agents.

Levothyroxine (LT4) is the mainstay treatment for hypothyroid disorders. TSH suppressive LT4 therapy consisting of high dosages of LT4 is an established component of the preventive management of thyroid carcinoma (TC) growth in patients with differentiated thyroid carcinoma (DTC). TSH suppression maintains those patients in a state of subclinical hyperthyroidism characterized by normal levels of the thyroid hormones, free thyroxine (fT4) and free triiodothyronine (fT3), and low levels of TSH. While thyroxine (T4) is less metabolically active than T3, short-term administration of LT4 has been shown to increase resting energy expenditure (REE) in normal males $(8,9)$.

The first aim of this study was to assess changes in body weight, body composition, REE, respiratory quotient (RQ), and metabolic parameters in female DTC patients, starting from the phase of a euthyroid state before total thyroidectomy and extending throughout the subsequent year after TSH suppression. The second aim was to assess the relationship between these variables and thyroid function parameters.

\section{Methods}

\section{Study design and population}

This is an observational case series study of 15 female DTC patients who were treated in the Institute of Endocrinology, Metabolism, and Hypertension at the Tel Aviv Sourasky Medical Center (TASMC) between January 1, 2013, and July 31, 2015. During the study period, all patients received standard treatment, including total thyroidectomy, in the TASMC Otolaryngology Department, followed by radioactive iodine $\left({ }^{131} \mathrm{I}\right)$ treatment and TSH suppressive therapy with LT4 according to ATA 2009 recommendations. LT4 doses were changed to achieve the minimum dose required for the target TSH level. Doses of LT4 were decreased (100-200 $\mu \mathrm{g} / \mathrm{week})$ if oversuppression was documented, or increased (100-200 $\mu \mathrm{g} /$ week) if TSH suppression had not been achieved. The last visit took place after the patient completed at least 12 months of TSH suppressive therapy.

\section{Inclusion criteria}

Women aged 18-65 years who had a primary DTC diagnosis with normal thyroid function and were candidates for total thyroidectomy, ${ }^{131}$ I treatment, and TSH suppressive LT4 therapy were suitable for study enrollment.

\section{Exclusion criteria}

Excluded were any patients who had previously been hypo- or hyperthyroid before thyroidectomy, known cardiovascular disease, history of a previous non-TC, and the use of any medication that alters body weight and composition (e.g., corticosteroids, insulin, sulfonylureas).

\section{Study procedure}

After recruitment to the study, the subjects were evaluated at each of five visits to the institute: (1) at the initial diagnosis of DTC before thyroidectomy (endogenous euthyroid state), (2) 2-3 weeks after thyroidectomy, before ${ }^{131}$ I treatment and to LT4 therapy (post-thyroidectomy hypothyroid state), (3) after ${ }^{131}$ I treatment and at least $4-12$ weeks of LT4 therapy (exogenous euthyroid state), (4) after completing at least 3-9 months of TSH suppressive LT4 therapy (exogenous subclinical hyperthyroid state), (5) after completing at least 12 months of TSH suppressive LT4 therapy (exogenous subclinical hyperthyroid state). All examinations were performed in the morning after an overnight 12-hour fast. Patients were instructed to avoid taking their LT4 doses on the day of examination to obviate variations in thyroid function tests due to the timing of the doses. Thyroid function measurements were performed at each of the five visits. Glucose and lipid profiles were drawn up at the beginning (visit 1) and at the end (visit 5) of the study.

\section{Anthropometry and body composition}

Weight was measured in light clothing on a digital electronic scale. Height was measured using a precision meter. BMI was calculated as the body weight $(\mathrm{kg})$ divided by the square of the body height $\left(\mathrm{m}^{2}\right)$. Body fat of the total body, trunk, upper and lower extremities, and lean body mass (LBM) were determined by using the dual energy X-ray absorptiometry method (Hologic QDR 4500 W, serial no. 49694; Waltham, MA). Body composition measurements were made at the beginning (visit 1) and at the end (visit 5) of the study.

\section{REE and energy intake}

Patients were instructed to continue their usual physical activities and diet during the study follow-up. REE was examined from 07.00 AM to 8.00 AM or from 08.00 AM to 09.00 AM by an open-circuit indirect calorimeter (Deltatrac; Datex, Helsinki, Finland). The patients were studied after a 12-hour overnight fast and in a $24^{\circ} \mathrm{C}$ temperature-controlled room, in quiet surroundings, and after 30 minutes of absolute rest. They were asked to stay awake and not to move during the examination. Concomitant measurements of oxygen consumption and carbon dioxide $\left(\mathrm{CO}_{2}\right)$ production were continuously sampled for 45-60 minutes to measure REE and to calculate the RQ $\left(\mathrm{RQ}=\mathrm{CO}_{2} / \mathrm{O}_{2}\right)$. RQ was determined between 1.0 (representing exclusive carbohydrate utilization) and 0.7 (representing exclusive lipid utilization). Calorimetric measurements were performed at each of the five visits. Patients were instructed to maintain their physical activity and diet during the study follow-up.

\section{Blood samples}

Blood tests, which included fasting glucose, total cholesterol, high-density lipoprotein (HDL) cholesterol, and triglycerides, were performed using an enzymatic method at the first and last visit. Low-density lipoprotein (LDL) cholesterol was calculated according to the Friedewald formula ( $\mathrm{LDL}=$ total cholesterol HDL cholesterol - triglycerides $/ 5 ; \mathrm{mg} / \mathrm{dL}$ ). Blood tests, which included TSH, fT4, and total triiodothyronine (TT3), were performed by means of immunoenzymatic methods (DPC, Los Angeles, CA) at each study visit. Reference values for 
thyroid function tests were as follows: TT3, 80-200 ng/dL; fT4, $0.7-1.8 \mathrm{ng} / \mathrm{dL}$; and TSH, $0.40-4.7 \mathrm{mIU} / \mathrm{L}$. All of the samples from the individual patients were run in the same assay.

\section{Statistical analysis}

All the data are described as means and standard deviations. The repeated measures analysis of variance test for related groups with continuous dependent variables and categorical independent variables was applied for comparisons between patient parameters during the study period. A generalized estimating equation analysis was performed to estimate the longitudinal correlations of the TT3/fT4 ratio (as an independent variable) with changes between the beginning of the study (visit 1) and the end of the study (visit 5) in the following parameters: weight, BMI, heart rate, systolic and diastolic blood pressures, fasting blood glucose, HDL cholesterol, LDL cholesterol, triglycerides, RQ, REE, REE as a percentage of predicted REE (REEPP), and body composition parameters (as dependent variables). REEPP was calculated based on the Harris and Benedict equation (10). The Tukey's range test was used for multiple testing analyses (comparisons). All tests were two-tailed. A $p$-value $<0.05$ was considered statistically significant. All data were analyzed using SAS $^{\circledR}$ version 9.1.3 (SAS Institute, Cary, NC).

\section{Ethical considerations}

The study was approved by the medical ethics committee of the TASMC. Written informed consent was obtained from all patients before enrollment.

\section{Results}

\section{Characteristics of the study population}

The clinical and pathological characteristics of the study population at the beginning and at the end of the study are listed in Table 1. The mean age of the 15 female DTC patients was $41.0 \pm 8.9$ years. They all underwent total thyroidectomy followed by ${ }^{131}$ I treatment and TSH suppressive LT4 therapy. Most of the patients achieved TSH suppression with normal fT4 and TT3 values, and only two patients (13\%) had slightly elevated fT4 levels, while their TT3 levels were within the low-normal range (Table 1).

\section{Thyroid function and metabolic parameters}

Table 2 presents the mean values of the metabolic parameters and of the thyroid function test results at the beginning (visits 1) and at the end (visit 5) of the study (spanning an average of 19 months). The TSH levels at visit 5 were lower than those at visit $1(0.09 \pm 0.16 \mathrm{mIU} / \mathrm{mL}$ vs. $2.01 \pm 1.37 \mathrm{mIU} / \mathrm{mL}$, respectively, $p<0.05)$, the fT4 levels were higher $(1.5 \pm 0.2 \mathrm{ng} / \mathrm{dL}$ vs. $1.0 \pm 0.17 \mathrm{ng} / \mathrm{dL}$, respectively, $p<0.05)$, and the respective TT3 levels and the TT3/ fT4 ratios were lower $(103.7 \pm 17.3$ vs. $122.9 \pm 19.0, p<0.05$ and $66.8 \pm 16.3$ vs. $122.2 \pm 22.8, p<0.001)$.

The mean heart rate values at visit 5 were higher than those of visit 1 ( $70 \pm 11.59$ vs. $64 \pm 7.05$ beats/minute, respectively, $p<0.05)$, as was systolic blood pressure $(120.92 \pm 10.18$ vs. $112.92 \pm 10.14 \mathrm{~mm} \mathrm{Hg}, p<0.001)$ and diastolic blood pressure $(75.83 \pm 9.6$ vs. $69.17 \pm 7.43 \mathrm{~mm} \mathrm{Hg}, p>0.001)$. There was an increase in the mean fasting blood glucose level and a decrease in the mean triglyceride level, both of borderline significance (Table 2).

\section{Body composition}

The mean values of BMI, fat mass, and LBM did not change significantly between visits 1 and 5 (Table 3 ). The increase in the mean value of fat percentage of the arms, however, was significant (from $35.97 \pm 12.63 \%$ to $40.58 \pm$ $40.58 \%, p<0.05)$

Table 1. Clinical and Pathological Data of the Women Diagnosed With Differentiated Thyroid Cancer $(N=15)$

\begin{tabular}{|c|c|c|c|c|c|c|c|c|c|c|c|}
\hline \multirow{2}{*}{$\begin{array}{l}\text { Patient } \\
\text { no. }\end{array}$} & \multirow{2}{*}{$\begin{array}{l}\text { Age at } \\
\text { diagnosis }\end{array}$} & \multirow[b]{2}{*}{ TNM staging } & \multirow[b]{2}{*}{ RI dose } & \multirow{2}{*}{$\begin{array}{c}\text { Response to } \\
\text { treatment }\end{array}$} & \multirow{2}{*}{$\begin{array}{c}\text { LT4 dose at } \\
\text { TSH suppression }\end{array}$} & \multicolumn{2}{|c|}{$T S H ~ m I U / m L$} & \multicolumn{2}{|c|}{$f T 4 n g / d L$} & \multicolumn{2}{|c|}{$T T 3 n g / d L$} \\
\hline & & & & & & $B S$ & $E S$ & $B S$ & $E S$ & $B S$ & $E S$ \\
\hline 1 & 58 & T3N1aM0 & 150 & Cured & 875 & 2.27 & 0.02 & 0.94 & 1.26 & 142.10 & 123.5 \\
\hline 2 & 45 & T3N0M0 & 100 & Cured & 900 & 1.80 & 0.09 & 1.26 & 1.57 & 112.27 & 70.47 \\
\hline 3 & 35 & T1bN1aM0 & 100 & Cured & 700 & 2.78 & 0.02 & 0.96 & 1.35 & 123.12 & 121.21 \\
\hline 4 & 33 & T1bN1aM0 & 100 & Cured & 700 & 1.71 & 0.20 & 1.31 & 2.01 & 126.86 & 103.01 \\
\hline 5 & 32 & T1bN1aM0 & 225 & SIR & 800 & 1.99 & 0.20 & 0.99 & 1.46 & 96.51 & 94.85 \\
\hline 6 & 35 & T1bN1bM0 & 150 & BPR & 1000 & 0.89 & 0.09 & 0.85 & 1.66 & 95.95 & 94.80 \\
\hline 7 & 43 & T1bN1aM0 & 30 & Cured & 900 & 0.61 & 0.01 & 1.05 & 1.50 & 138.93 & 138.69 \\
\hline 8 & 30 & T3N0M0 & 30 & BPR & 800 & 2.32 & 0.01 & 1.30 & 1.39 & 139 & 99.18 \\
\hline 9 & 41 & T3NOMO & 100 & Cured & 850 & 1.90 & 0.04 & 0.90 & 1.30 & 106.29 & 82.33 \\
\hline 10 & 26 & T3N1bM0 & 150 & BPR & 800 & 3.11 & 0.01 & 0.98 & 1.54 & 149.33 & 97.13 \\
\hline 11 & 30 & T3N1bM0 & 150 & Cured & 850 & 0.26 & 0.09 & 1.20 & 1.36 & 108.05 & 95.27 \\
\hline 12 & 65 & T1bN1aM0 & 50 & Cured & 800 & 5.20 & 0.01 & 0.77 & 2.10 & 112.45 & 98.82 \\
\hline 13 & 44 & T3N1aMo & 150 & Cured & 850 & 4.17 & 0.10 & 0.88 & 1.71 & 126.12 & 105.91 \\
\hline 14 & 43 & T1bN1aM0 & 150 & Cured & 1050 & 1.32 & 0.5 & 1.06 & 1.45 & 156.74 & 122.36 \\
\hline 15 & 51 & T3NOM0 & 30 & Cured & 750 & 1.35 & 0.01 & 0.92 & 1.51 & 110.2 & 108.66 \\
\hline
\end{tabular}

${ }^{\mathrm{a}}$ The dose of LT4 per week.

BPR, biochemical partial response; BS, beginning of the study, euthyroid state; ES, end of the study, subclinical hyperthyroid state; fT4, free thyroxine; LT4, levothyroxine; RI, radioiodine; SIR, structural incomplete response; TNM, tumor, lymph node, metastasis; TSH, thyrotropin; TT3, total triiodothyronine. 
Table 2. Physical and Blood Chemistry Data of the Women Diagnosed with Differentiated Thyroid CANCER $(N=15)$

\begin{tabular}{|c|c|c|c|}
\hline Parameter & $\begin{array}{c}\text { Beginning of the study } \\
\text { Euthyroid state } \\
\text { Mean } \pm \text { SD, median [Q1-Q3] }\end{array}$ & $\begin{array}{l}\text { End of the study } \\
\text { Subclinical hyperthyroid state } \\
\text { Mean } \pm S D \text {, median }[Q 1-Q 3]\end{array}$ & $\mathrm{p}$ \\
\hline Age, years & $40.7 \pm 8.9,41.0[32.0-45.0]$ & & \\
\hline Weight, $\mathrm{kg}$ & $66.7 \pm 11.4,67.6[55-73]$ & $68.6 \pm 12.3,68.9[56.7-76.5]$ & 0.41 \\
\hline Heart rate, bpm & $64 \pm 7.1,66.0[60.0-72.0]$ & $70 \pm 11.6,67.5[63.5-80.5]$ & 0.01 \\
\hline Systolic BP, mm Hg & $112.9 \pm 10.1,110.0[101.0-21.0]$ & $120.9 \pm 10.2,117.0[113-132]$ & $<0.001$ \\
\hline Diastolic $\mathrm{BP}, \mathrm{mm} \mathrm{Hg}$ & $69.2 \pm 7.4,66[62-72]$ & $75.8 \pm 9.6,72.5[70.5-85.0]$ & $<0.001$ \\
\hline $\mathrm{FBG}, \mathrm{mg} / \mathrm{dL}$ & $83.9 \pm 11.7,81.0[78.0-87.0]$ & $88.0 \pm 17.3,84[81.0-98.0]$ & 0.07 \\
\hline HDL cholesterol, $\mathrm{mg} / \mathrm{dL}$ & $53.4 \pm 9.1,57.0[53.0-59.0]$ & $50.0 \pm 8.4,50.0[44.7-56.0]$ & 0.15 \\
\hline LDL cholesterol, $\mathrm{mg} / \mathrm{dL}$ & $91.6 \pm 14.0,9[80.0-106.0]$ & $87.4 \pm 17.1,88[69.0-102.0]$ & 0.14 \\
\hline Triglycerides, mg/dL & $96.0 \pm 34.0,91.5[82.0-123.0]$ & $78.8 \pm 26.9,77[62-105.0]$ & 0.07 \\
\hline $\mathrm{TSH}, \mathrm{mIU} / \mathrm{mL}$ & $2.0 \pm 1.4,1.85[1.32-2.78]$ & $0.1 \pm 0.2,0.03[0.01-0.09]$ & 0.004 \\
\hline $\mathrm{fT} 4, \mathrm{ng} / \mathrm{dL}$ & $1.0 \pm 0.2,0.98[0.9-1.2]$ & $1.5 \pm 0.2,1.48[1.4-1.7]$ & 0.005 \\
\hline $\mathrm{TT} 3, \mathrm{ng} / \mathrm{dL}$ & $122.9 \pm 19.0,123.1[108.1-139.0]$ & $103.7 \pm 17.3,99.2[94.9-121.2]$ & 0.02 \\
\hline TT3/fT4 & $122.2 \pm 22.8,119.8[97.5-146.0]$ & $68.8 \pm 16.3,65.0[57.1-84.4]$ & $>0.001$ \\
\hline
\end{tabular}

BP, blood pressure; FBG, fasting blood glucose; HDL, high-density lipoprotein; LDL, low-density lipoprotein; SD, standard deviation.

\section{Energy expenditure}

RQ significantly decreased during the follow-up period ( $p$ for trend $<0.05$ ) (Fig. 1A). Interestingly, there was a rapid change in RQ (Fig. 1A) in parallel with rapid thyroid function changes (Fig. 1B). Patients in a hypothyroid state underwent elevation of RQ (visit 2). Euthyroid LT4-treated thyroidectomy patients underwent a reduction of RQ (visit 3) to a level similar to the euthyroid value at the beginning of the study (visit 1). The same RQ level as in visit 3 was found at the beginning of exogenous subclinical hyperthyroidism (visit 4). Patients with continuing exogenous subclinical hyperthyroidism (visit 5) underwent subsequent RQ level reduction. Opposite changes of REE were seen at the same time points (Fig. 1C).

REE and REE per kilogram of lean body mass (REE/ LBM) were significantly increased at visit 5 compared to visit $1[1476 \pm 137.49 \mathrm{kcal} / \mathrm{day}$ and $38.5 \pm 3.4 \mathrm{kcal} /(\mathrm{d} \cdot \mathrm{kg}) \mathrm{vs}$.
$1376.7 \pm 178.24 \mathrm{kcal} / \mathrm{day}$ and $35.93 \pm 4.29 \mathrm{kcal} /(\mathrm{d} \cdot \mathrm{kg})$, respectively, $p<0.05]$. Three of the women participating in the study were postmenopausal (no menstruation for the preceding 12 months or longer). After stratification of the study population according to menstrual status, there was no difference in REE/LBM between the pre- and postmenopausal women $(p=0.6)$.

\section{Associations between TT3/fT4 ratios and metabolic parameters}

Longitudinal correlations, after adjustment for age, between the TT3/fT4 ratio and anthropometric and metabolic parameters revealed a positive correlation of TT3/fT4 with RQ ( $\beta=0.77, p<0.05)$, and a negative correlation of TT3/fT4 with BMI $(\beta=-0.41, p<0.05)$, systolic blood pressure $(\beta=-0.25$, $p<0.05)$, fasting blood glucose $(\beta=-0.37, p<0.05)$, android

Table 3. Anthropometric and Body Composition Data of the Women Diagnosed With Differentiated Thyroid Cancer $(N=15)$

\begin{tabular}{|c|c|c|c|}
\hline Parameter & $\begin{array}{c}\text { Beginning of the study } \\
\text { Euthyroid state } \\
\text { Mean } \pm S D, \text { median }[Q 1-Q 3]\end{array}$ & $\begin{array}{c}\text { End of the study } \\
\text { Subclinical hyperthyroid state } \\
\text { Mean } \pm S D \text {, median }[Q 1-Q 3]\end{array}$ & $\mathrm{p}$ \\
\hline $\mathrm{BMI}, \mathrm{kg} / \mathrm{m}^{2}$ & $25.3 \pm 5.0,25.9[22.6-30.7]$ & $25.5 \pm 4.4,26.4[23.3-31.3]$ & 0.62 \\
\hline Fat mass, $\mathrm{kg}$ & $37.8 \pm 10.7,39.2[33.9-45.8]$ & $38.0 \pm 10.8,37.5[34.0-50.1]$ & 0.31 \\
\hline Arms, $\%$ & $36.0 \pm 12.6,34.8[27.2-44.3]$ & $40.6 \pm 40.6,36.6[34.0-50.5]$ & 0.002 \\
\hline Legs, \% & $38.3 \pm 9.1,38.0[34.7-46.7]$ & $38.7 \pm 10.3,38.6[31.9-47.2]$ & 0.78 \\
\hline Trunk, $\%$ & $37.1 \pm 12.0,36.4[34.4-43.7]$ & $38.9 \pm 11.5,40.2[33.6-47.6]$ & 0.2 \\
\hline Android, ${ }^{\text {a }} \%$ & $37.5 \pm 13.0,38.6[34.2-45.9]$ & $39.8 \pm 12.7,43.4[32.3-46.5]$ & 0.15 \\
\hline Gynoid, ${ }^{\mathrm{b}} \%$ & $41.2 \pm 8.5,43.0[37.8-46.2]$ & $40.8 \pm 8.4,41.0[37.8-48.4]$ & 0.82 \\
\hline LBM, kg & $37.7 \pm 3.9,37.1[37.4-40.3]$ & $35.4 \pm 2.0,37.5[34.9-41.0]$ & 0.75 \\
\hline $\mathrm{REE}, \mathrm{kcal} / \mathrm{day}$ & $1376.7 \pm 178.2,1358.0[1272.0-1409.0]$ & $1476.0 \pm 137.5,1479.0[1363.0-1546.0]$ & 0.008 \\
\hline $\mathrm{REE} / \mathrm{LBM}, \mathrm{kcal} /(\mathrm{d} \cdot \mathrm{kg})$ & $35.9 \pm 4.3,37.3[34.6-38.5]$ & $38.5 \pm 3.4,38.0[36.2-39.9]$ & 0.026 \\
\hline REEPP, \% & $100.0 \pm 5.7,97.6[94.3-100.7]$ & $105.5 \pm 13.3,108.1[103.7-116.3]$ & 0.2 \\
\hline $\mathrm{RQ}$ & $0.87 \pm 0.06,0.88[0.81-0.91]$ & $0.82 \pm 0.06,0.81[0.78-0.85]$ & 0.02 \\
\hline
\end{tabular}

${ }^{\mathrm{a}}$ Abdominal wall and visceral mesentery fat distribution.

${ }^{\mathrm{b}}$ Body type with more fat deposited in the hips, buttocks and thighs.

BMI, body mass index; LBM, lean body mass; REE, rest energy expenditure; REEPP, rest energy expenditure as a percentage of predicted REE based on the Harris and Benedict equation; RQ, respiratory quotient. 

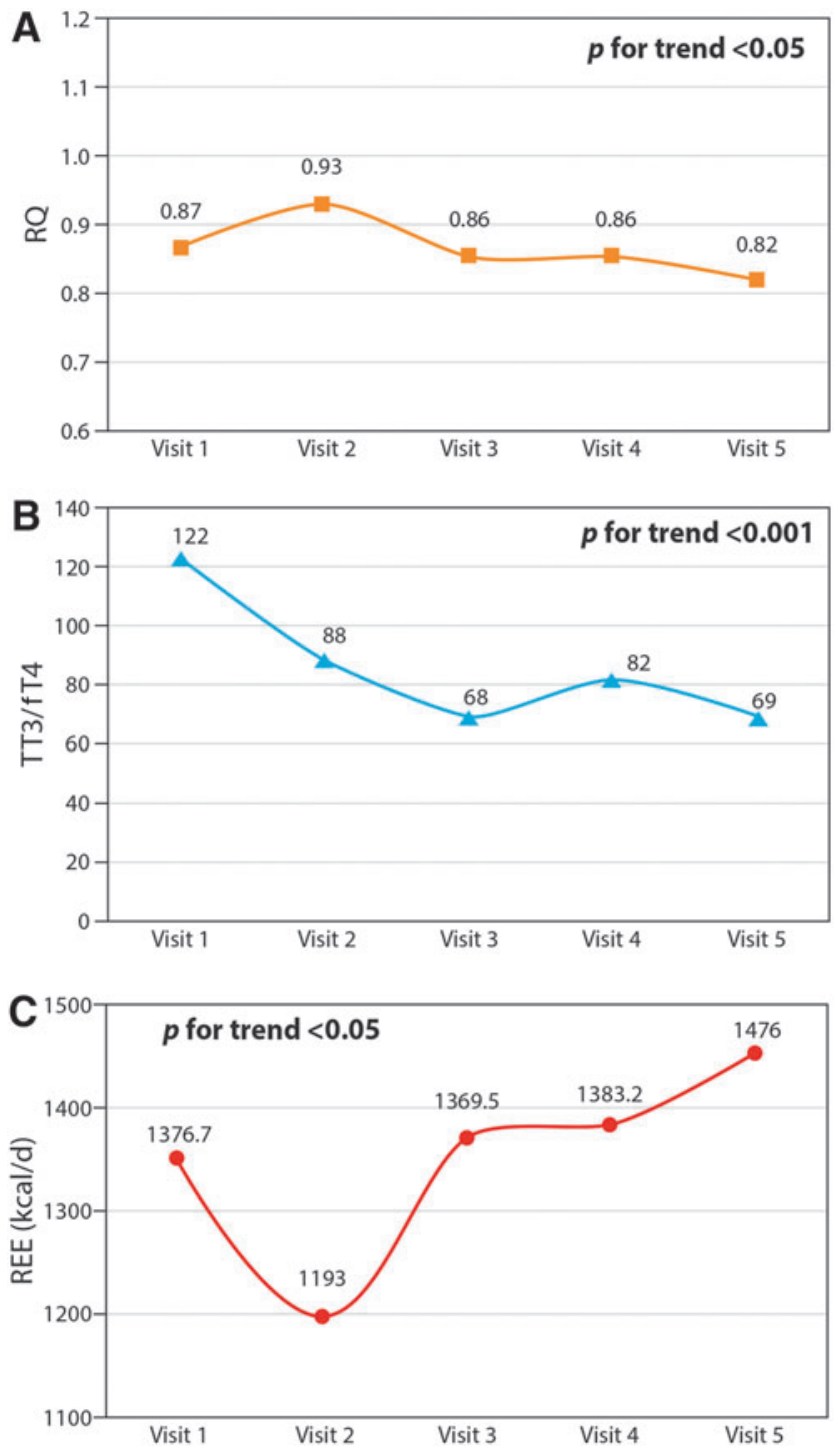

FIG. 1. (A) The RQ changes during the follow-up periods of the study. (B) The TT3/fT4 ratio changes during the follow-up periods of the study. (C) The REE changes during the follow-up periods of the study. Visit 1 - endogenous euthyroid state, the initial diagnosis of differentiated thyroid cancer before thyroidectomy. Visit 2-post-thyroidectomy hypothyroid state, 2-3 weeks after thyroidectomy, before ${ }^{131}$ I treatment and to LT4 therapy. Visit 3-exogenous euthyroid state, after ${ }^{131}$ I treatment and completing at least 4-12 weeks of LT4 therapy. Visit 4-exogenous subclinical hyperthyroid state, after completing at least 3-9 months of TSH suppressive LT4 therapy. Visit 5-exogenous subclinical hyperthyroid state, after completing at least 12 months of TSH suppressive LT4 therapy. ${ }^{13 \mathrm{I}}$ I, radioactive iodine; fT4, free thyroxine; LT4, levothyroxine; REE, rest energy expenditure; RQ, respiratory quotient; TSH, thyrotropin; TT3, total triiodothyronine.

(abdominal wall and visceral mesentery) fat distribution, and trunk (abdomen, chest, shoulder, and nape of the neck) fat distribution $(\beta=-0.33$ and $\beta=-0.36$, respectively, $p<0.05)$, arm fat distribution $(\beta=-0.76, p<0.0001)$, REE $(\beta=-0.66$, $p<0.001)$, and $\operatorname{REE} / \operatorname{LBM}(\beta=-0.78, p<0.001)$. There was no relationship between the LT4 dose and the T3/T4 ratio.

\section{Discussion}

The major findings of this study of female patients with DTC were that treatment with thyroidectomy and ${ }^{131}$ I treatment followed by TSH suppressive LT4 therapy yielded an increase in REE and REE/LBM while the BMI and the LBM did not change significantly. In addition, there was a significant increase in a number of cardiovascular risk factors, including heart rate and systolic and diastolic blood pressures. Concomitantly, there was an increase in the fT4 level, while the TT3/fT4 ratios, the TSH levels, and the RQs decreased.

\section{EE and body composition}

Similar to our findings, a recently published longitudinal study of 8 female DTC patients and 2 male DTC patients reported a higher basal metabolic rate in the subclinical hyperthyroid state after 6 months of LT4 suppressive therapy compared with their hypothyroid state before the initiation of LT4 therapy (11). BMI did not change during the follow-up period in that study. In another recently published crosssectional study, women who received TSH suppressive LT4 therapy for 1-25 years had comparable values of BMI and LBM, but a higher REE/LBM compared with non-LT4treated euthyroid women and to hypothyroid women treated with chronic replacement LT4 doses (12). The authors did not have a clear-cut explanation for the similar BMI values, despite the differences in REE. Only 16 of the 26 women in the suppressive LT4 group were diagnosed with DTC, while the other 10 were unintentionally overtreated with LT4 for nonmalignant disease. One prospective interventional study reported unchanged body composition in euthyroid subjects treated with LT4 to reach low-normal TSH target levels compared with nonLT4-treated euthyroid subjects (13). Another prospective interventional study on hypothyroid LT4-treated patients did not reveal any changes in body composition between those who reached low-normal and high-normal THS target levels (14). An earlier investigation of 29 women and 12 men who underwent thyroidectomy for DTC and received TSH suppressive LT4 therapy reported a nonsignificant increase in basal EE and no significant difference in body composition compared with the control group (15).

In this study, as well as in the others already described $(1,2)$, the increased REE and REE/LBM in the subclinical hyperthyroid state would be expected to result in the presence of a decreased BMI, but there are apparently factors, such as the thyroidectomy itself, iatrogenic hyperthyroidism, and the presence of DTC, which blunt a shift in this direction. Moreover, controlling for the unique effect of cancer does not yield consistent findings. A retrospective study reported greater weight gain among patients who had undergone thyroidectomy for benign thyroid disease during the previous year than among those with hypothyroidism, iatrogenic hyperthyroidism, or without thyroid disease (16). Those authors suggested thyroid replacement therapy and thyroidectomy as possible factors contributing to weight gain. However, in a longitudinal study of women who were treated with LT4 replacement therapy after thyroidectomy for benign multinodular goiter, no significant changes in body mass or body composition were observed during the 12 months after surgery (17). In another longitudinal study of patients after total thyroidectomy for benign multinodular goiter who had been 
treated with LT4 replacement therapy, weight gain was similar for those who had subclinical hypothyroidism and those who were euthyroid at six months (18).

The presence of DTC adds a factor that may directly affect body weight, body composition, and EE, in addition to thyroidectomy and thyroid replacement therapy. Our findings of stable LBM concur with those of another study of patients treated with T4 after thyroidectomy for DTC (19). A recently published meta-analysis reported increased REE in cancer patients compared with controls: the increase was most pronounced in patients with cancers of metabolically demanding organs (20).

There was no longitudinal control group in this study. Several studies have shown that REE and body composition decrease with age (21-23), a process that starts between 30 and 45 years of age. Moreover, there are several age-specific prediction algorithms in the literature $(21,23)$. We, therefore, assume that a control group would have shown decreased REE and body composition over the course of a year, and that the inclusion of a control group would make our data more significant.

We found a significant increase in REE (by $100 \mathrm{kcal} / \mathrm{day}-$ $7.3 \%, p<0.05$ ) and in REE/LBM from the beginning (euthyroid state) to the end of the study (subclinical hyperthyroid state). However, no significant changes in BMI or body composition were observed. One of the probable explanations for this finding may be high-normal fT4 levels achieved under LT4 treatment. The role of decreased TT3 in this situation remains questionable. Other components, such as energy intake through diet and physical activity equivalent to total EE may have changed to compensate for the increased REE, therefore, maintaining a stable body weight and body composition (24).

\section{Thyroid function and arterial blood pressure parameters}

The mean values of systolic and diastolic blood pressures at the subclinical hyperthyroidism phase were higher than those before thyroidectomy among our patients. In a general population study, endogenous subclinical hyperthyroidism (decreased and suppressed TSH levels: $<0.25$ and $<0.1 \mathrm{mIU} /$ L, respectively) was not associated with hypertension (25). Furthermore, the authors of a cross-sectional study of individuals without thyroid disease concluded that endogenous subclinical hyperthyroidism is not associated with hypertension (26). A meta-analysis of cross-sectional data from seven studies reported that endogenous subclinical hyperthyroidism was not associated with increased systolic and diastolic blood pressures (27). These observations raise the possibility that DTC or thyroidectomy may be at the base of the association between the exogenous subclinical hyperthyroidism and increased blood pressure demonstrated in this study.

\section{Associations between the TT3/fT4 ratio and metabolic parameters}

Several earlier studies investigated the effects of T4, T3, and the T3/T4 ratio on metabolic, body composition, and calorimetric parameters. We chose to use the T3/T4 ratio as an independent variable to minimize multiple comparisons in this relatively small study population. The TT3/fT4 ratio in the exogenous subclinical hyperthyroid state was lower than the baseline euthyroid state in this study. This finding was in conjunction with a less favorable metabolic profile manifested by higher BMI, fasting blood glucose, and systolic blood pressure values. This is in contrast with associations reported between a higher TT3/fT4 ratio and components of the metabolic syndrome in healthy middle-aged non-LT4treated euthyroid men and women $(28,29)$, and the association of a higher TT3/fT4 ratio with a less favorable metabolic phenotype in pregnant non-LT4-treated euthyroid women without a history of thyroid dysfunction (30).

The positive association between TT3/fT4 and RQ over time, after adjusting for age, indicates that the TT3/fT4 ratio may have nutritional implications, that is, the lower the ratio, the better the fat utilization. To the best of our knowledge, this relationship has not been described before in the literature. In healthy individuals, increased exogenous TT3 was shown to reduce insulin sensitivity (31), decrease fat and fatfree mass, increase EE (32), and increase thermogenesis, in part, by promoting the uncoupling of mitochondrial energy in skeletal muscle (33). Interestingly, no differences in carbohydrate, fat, and protein oxidation were found among women receiving chronic TSH-suppressive LT4 doses, and who presumably had an increased TT3/fT4 ratio. Similarly, no differences were observed between them and women receiving chronic replacement LT4 doses, or between untreated euthyroid control women (12).

Thyroidectomized patients are characterized by the lack of both T3 and T4 secretions. In this study, LT4 treatment at TSH suppressive doses was achieved with high-normal fT4 levels in $87 \%$ of the female DTC patients or slightly elevated fT4 levels in $13 \%$ of them. Type 2 deiodinase (D2) converts T4 in T3 in several human tissues and plays a cardinal role in the negative feedback regulation of TSH secretion. One of the explanations for an elevated fT4 and decreased TT3 levels may be a common polymorphism of D2, threonine 92 alanine, that is associated with decreased D2 enzymatic activity and has been shown as being a predictor for higher $\mathrm{T} 4$ intake to suppress TSH in thyroidectomized patients $(34,35)$. Another explanation for this finding may be the direct inhibitory effect of elevated T4 on D2, which may explain, at least in part, the lower TT3/fT4 ratio. However, attempts with L-triiodothyronine/LT4 combination therapy have not been proven to be a better option than LT4, nor have they demonstrated weight or BMI changes in randomized controlled trials, including meta-analyses $(36,37)$.

We are not aware of any other investigations of the TT3/ fT4 ratio and REE. In this report, we describe an inverse relationship between the TT3/fT4 ratio and REE, after age adjustment, in a small cohort followed longitudinally. We also describe an inverse relationship between TSH and REE. The latter finding is in contrast with the lack of association between REE and TSH reported in cross-sectional studies of non-LT4-treated euthyroid persons (38), as well as in severely obese non-LT4-treated euthyroid persons (39). However, our findings concur with the inverse association between TSH and REE observed in a cross-sectional study of non-LT4-treated euthyroid elderly women but not men (40), and to those of a longitudinal study of nine hypothyroid patients on chronic LT4 treatment who were subjected to small changes in TSH (41). In another study, the resting metabolic rate in healthy euthyroid males increased from $1612 \pm 142$ to 
$1672 \pm 129(p=0.06)$, and the resting RQ increased from $0.83 \pm 0.03$ to $0.85 \pm 0.03(p=0.02)$, after taking $200 \mathrm{mg}$ T4 for only 3 days (8).

An interesting finding of this study is the negative correlation between the TT3/fT4 ratio and the fat distribution in the arm, trunk, as well as abdominal wall and visceral mesentery (android fat), after adjustment for age. The TT3/fT4 ratio, as well as the insulin levels, and components of the metabolic syndrome were higher among obese non-LT4treated euthyroid women with central obesity compared with those with peripheral obesity and nonobese controls (42).

The main strength of this study is its longitudinal design in which the participants served as their own controls. The absence of comparative groups, however, limited our ability to distinguish the observed effects from those of thyroidectomy surgery for benign disease and from those of LT4 therapy that is not TSH suppressive. All of our subjects were women, thus generalization to men is not possible. Another limitation of this study is that we measured total TT3 and not fT3, as is the practice in our hospital laboratory.

In conclusion, the increased REE, decreased RQ, abdominal fat distribution, and poorer metabolic profile of the women in our cohort may result from a combination of the following factors: the presence of DTC, thyroidectomy, LT4 treatment, and the exogenous subclinical hyperthyroid state characterized by a low TT3/fT4 ratio. Since current evidence does not enable a better resolution of these potentially causative factors, our findings support those that questioned the extent of TSH suppression (43), as well as the research and guidelines that advocate TSH suppression solely for patients at high risk of DTC recurrence (44). Our findings also suggest the need for more research on an evaluation of metabolic changes, at least in female DTC patients with a low TT3/fT4 ratio on TSH suppression.

\section{Acknowledgments}

The authors thank Ms. Mira Arbiv for her help in performing the calorimeter examinations. This study had been done in partial fulfillment of the requirements for a $\mathrm{PhD}$ degree of Elena Izkhakov, supervised by Dr. Lital KeinanBoker and Dr. Micha Barchana, School of Public Health, University of Haifa, Haifa, Israel.

\section{Author Disclosure Statement}

All authors have nothing to declare.

\section{References}

1. Bianco AC, Maia AL, da Silba WS, Christoffolete MA 2005 Adaptive activation of thyroid hormone and energy expenditure. Biosci Rep 25:191-208.

2. Kim B 2008 Thyroid hormone as a determinant of energy expenditure and the basal metabolic rate. Thyroid 18:141-144.

3. Iacobellis G, Ribaudo MC, Zappaterreno A, Iannucci CV, Leonetti F 2005 Relationship of thyroid function with body mass index, leptin, insulin sensitivity and adiponectin in euthyroid obese women. Clin Endocrinol (Oxf) 62:487-491.

4. Roos A, Bakker SJ, Links TP, Gans RO, Wolffenbuttel BH 2007 Thyroid function is associated with components of the metabolic syndrome in euthyroid subjects. J Clin Endocrinol Metab 92:491-496.
5. Diez JJ, Ijlesias P 2011 Relationship between thyrotropin and body mass index in euthyroid subjects. Exp Clin Endocrinolo Diabetes 119:144-150.

6. Roef G, Lapauw B, Goemaere S, Zmierczak HG, Toye K, Kaufman JM, Taes Y 2012 Body composition and metabolic parameters are associated with variation in thyroid hormone levels among euthyroid young men. Eur J Endocrinol 167:719-726.

7. Reinehr T, Isa A, de Sousa G, Dieffenbach R, Andler W 2008 Thyroid hormones and their relation to weight status. Horm Res 70:51-57.

8. Bracco D, Morin O, Liang H, Jequier E, Burger AG, Schutz Y 1996 Changes in sleeping and basal energy expenditure and substrate oxidation induced by short term thyroxin administration in man. Obes Res 4:213-219.

9. Johannsen DL, Galgani JE, Johannsen NM, Zhang Z, Covington JD, Ravussin E 2012 Effect of short-term thyroxine administration on energy metabolism and mitochondrial efficiency in humans. PLoS One 7:e40837.

10. Harris J, Benedict FG 1919 A Biometric Study of Basal Metabolism in Man. Publication No.279. Carnegie Institution of Washington, Washington, DC.

11. Broeders EP, Vijgen GH, Havekes B, Bouvy ND, Mottaghy FM, Kars M, Schaper NC, Schrauwen P, Brans B, van Marken Lichtenbelt WD 2016 Thyroid hormone activates brown adipose tissue and increases non-shivering thermogenesis-a cohort study in a group of thyroid carcinoma patients. PLoS One 11:e0145049.

12. Samuels MH, Kolobova I, Smeraglio A, Peters D, Purnell JQ, Schuff KG 2016 Effects of levothyroxine replacement or suppressive therapy on energy expenditure and body composition. Thyroid 26:347-355.

13. Dubois S, Abraham P, Rohmer V, Rodien P, Audran M, Dumas JF, Ritz P 2008 Thyroxine therapy in euthyroid patients does not affect body composition or muscular function. Thyroid 18:13-19.

14. Boeving A, Paz-Filho G, Radominski RB, Graf H, Amaral de Carvalho G 2011 Low-normal or high-normal thyrotropin target levels during treatment of hypothyroidism: a prospective, comparative study. Thyroid 21:355-360.

15. Wolf M, Weigert A, Kreymann G 1996 Body composition and energy expenditure in thyroidectomized patients during short-term hypothyroidism and thyrotropin-suppressive thyroxine therapy. Eur J Endocrinol 134:168-173.

16. Jonklaas J, Nsouli-Maktabi H 2011 Weight changes in euthyroid patients undergoing thyroidectomy. Thyroid 21: $1343-1351$.

17. Kormas N, Diamond T, O'Sullivan A, Smerdely P 1998 Body mass and body composition after total thyroidectomy for benign goiters. Thyroid 8:773-776.

18. Ozdemir S, Ozis ES, Gulpinar K, Aydin TH, Suzen B, Korkmaz A 2010 The effects of levothyroxine substitution on body composition and body mass after total thyroidectomy for benign nodular goiter. Endocr Regul 44:147-153.

19. Wu TJ, Huang SM, Taylor RL, Kao PC 2003 Thyroxine effects on serum insulin-like growth factor I levels, anthropometric measures, and body composition in patients after thyroidectomy. Ann Clin Lab Sci 33:423-428.

20. Nguyen TY, Batterham MJ, Edwards C 2016 Comparison of resting energy expenditure between cancer subjects and healthy controls: a meta-analysis. Nutr Cancer 68:374-387.

21. Müller MJ, Wang Z, Heymsfield SB, Schautz B, BosyWestphal A 2013 Advances in the understanding of specific 
metabolic rates of major organs and tissues in humans. Curr Opin Clin Nutr Metab Care 16:501-508.

22. Geisler C, Braun W, Pourhassan M, Schweitzer L, Gluer CC, Bosy-Westphal A, Muller MJ 2015 Gender-specific associations in age-related changes in resting energy expenditure (REE) and MRI measured body composition in healthy caucasians. J Gerontol A Biol Sci Med Sci 20:329335.

23. Wang Z, Ying Z, Bosy-Westphal A, Zhang J, Schautz B, Later W, Heymsfield SB, Muller MJ 2010 Specific metabolic rates of major organs and tissues across adulthood: evaluation by mechanistic model of resting energy expenditure. Am J Clin Nutr 92:1369-1377.

24. Van Zant RS 1992 Influence of diet and exercise on energy expenditure-a review. Int J Sport Nutr 2:1-19.

25. Volzke H, Alte D, Dorr M, Wallaschofski H, John U, Felix SB, Rettig R 2006 The association between subclinical hyperthyroidism and blood pressure in a population-based study. J Hypertens 24:1947-1953.

26. Walsh JP, Bremner AP, Bulsara MK, O'Leary P, Leedman PJ, Feddema P, Michelangeli V 2006 Subclinical thyroid dysfunction and blood pressure: a community-based study. Clin Endocrinol (Oxf) 65:486-491.

27. Cai Y, Ren Y, Shi J 2011 Blood pressure levels in patients with subclinical thyroid dysfunction: a meta-analysis of cross-sectional data. Hypertens Res 34:1098-1105.

28. Roef GL, Rietzschel ER, Van Daele CM, Taes YE, De Buyzere ML, Gillebert TC, Kaufman JM 2014 Triiodothyronine and free thyroxine levels are differentially associated with metabolic profile and adiposity-related cardiovascular risk markers in euthyroid middle-aged subjects. Thyroid 24:223-231.

29. Kim HJ, Bae JC, Park HK, Byun DW, Suh K, Yoo MH, Kim JH, Min YK, Kim SW, Chung JH 2016 Triiodothyronine levels are independently associated with metabolic syndrome in euthyroid middle-aged subjects. Endocrinol Metab (Seoul) 31:311-319.

30. Bassols J, Prats-Puig A, Soriano-Rodriguez P, GarciaGonzalez MM, Reid J, Martinez-Pascual M, MateosComeron F, de Zegher F, Ibanez L, Lopez-Bermejo A 2011 Lower free thyroxin associates with a less favorable metabolic phenotype in healthy pregnant women. J Clin Endocrinol Metab 96:3717-3723.

31. Dimitriadis G, Baker B, Marsh H, Mandarino L, Rizza R, Bergman R, Haymond M, Gerich J 1985 Effect of thyroid hormone excess on action, secretion, and metabolism of insulin in humans. Am J Physiol 248:E593-E601.

32. Lovejoy JC, Smith SR, Bray GA, DeLany JP, Rood JC, Gouvier D, Windhauser M, Ryan DH, Macchiavelli R, Tulley R 1997 A paradigm of experimentally induced mild hyperthyroidism: effects on nitrogen balance, body composition, and energy expenditure in healthy young men. $\mathbf{J}$ Clin Endocrinol Metab 82:765-770.

33. Lebon V, Dufour S, Petersen KF, Ren J, Jucker BM, Slezak LA, Cline GW, Rothman DL, Shulman GI 2001 Effect of triiodothyronine on mitochondrial energy coupling in human skeletal muscle. J Clin Invest 108:733-737.

34. Heemstra KA, Soeters MR, Fliers E, Serlie MJ, Burggraaf J, van Doorn MB, van der Klaauw AA, Romijn JA, Smit JW, Corssmit EP, Visser TJ 2009 Type 2 deiodinase polymorphism (threonine 92 alanine) predicts L-thyroxine dose to achieve target thyrotropin levels in thyroidectomized patients. J Clin Endocrinol Metab 94:2144-2150.

35. Castagna MG, Dentice M, Cantara S, Ambrosio R, Maino F, Porcelli T, Marzocchi C, Garbi C, Pacini F, Salvatore D 2017 DIO2 Thr92Ala reduces deiodinase-2 activity and serum-T3 levels in thyroid-deficient patients. J Clin Endocrinol Metab 102: 1623-1630.

36. Grozinsky-Glasberg S, Fraser A, Nahshoni E, Weizman A, Leibovich L 2006 Thyroxine-triiodothyronine combination therapy versus thyroxine monotherapy for clinical hypothyroidism: meta-analysis of randomized controlled trials. J Clin Endocr Metab 91:2592-2599.

37. Hoermann R, Midgley J, Larisch R, Dietrich JW 2018 Lessons from randomised clinical trials for triiodothyronine treatment of hypothyroidism: have they achieved their objectives? J Thyroid Res 2018:3239197.

38. Spadafranca A, Cappelletti C, Leone A, Vignati L, Battezzati A, Bedogni G, Bertoli S 2015 Relationship between thyroid hormones, resting energy expenditure and cardiometabolic risk factors in euthyroid subjects. Clin Nutr 34: 674-678.

39. Tagliaferri GC, Liuzzi A 2001 Subclinical hypothyroidism in obese patients: relation to resting energy expenditure, serum leptin, body composition, and lipid profile. Obes Res 9:196-201.

40. Nagel A, Spinneker A, Neuhäuser-Berthold M 2016 Association of thyroid-stimulating hormone with resting energy expenditure in euthyroid elderly subjects: a crosssectional study. Ann Nutr Metab 68:12-18.

41. al-Adsani H, Hoffer LJ, Silva JE 1997 Resting energy expenditure is sensitive to small dose changes in patients on chronic thyroid hormone replacement. J Clin Endocrinol Metab 82: 1118-1125.

42. Aras Ş, Üstünsoy S, Armutçu F 2015 Indices of central and peripheral obesity; anthropometric measurements and laboratory parameters of metabolic syndrome and thyroid function. Balkan Med J 32:414-420.

43. Sugitani I, Fujimoto Y 2010 Does postoperative thyrotropin suppression therapy truly decrease recurrence in papillary thyroid carcinoma? A randomized controlled trial. J Clin Endocrinol Metab 95:4576-4583.

44. Haugen BR, Alexander EK, Bible KC, Doherty GM, Mandel SJ, Nikiforov YE, Pacini F, Randolph GW, Sawka AM, Schlumberger M, Schuff KG, Sherman SI, Sosa JA, Steward DL, Tuttle RM, Wartofsky L 2016 American Thyroid Association Management guidelines for adult patients with thyroid nodules and differentiated thyroid cancer: the American Thyroid Association guidelines task force on thyroid nodules and differentiated thyroid cancer. Thyroid 26:1-133.

Address correspondence to: Elena Izkhakov, $M D, P h D$ Institute of Endocrinology, Metabolism and Hypertension Tel Aviv Sourasky Medical Center 6 Weizmann Street Tel Aviv 64233 Israel

E-mail: elenaiz@tlvmc.gov.il 